\title{
KORELASI ANTARA DENYUT NADI DAN INDEKS MASSA TUBUH (IMT) TERHADAP HASIL PENAMPILAN ATLET SENAM RITMIK POPDA SD KOTA SEMARANG TAHUN 2017
}

\author{
Yulfani Silva Rizqianti ${ }^{1}$, Ipang Setiawan ${ }^{2}$, Mugiyo Hartono ${ }^{3}$
}

Universitas Negeri Semarang

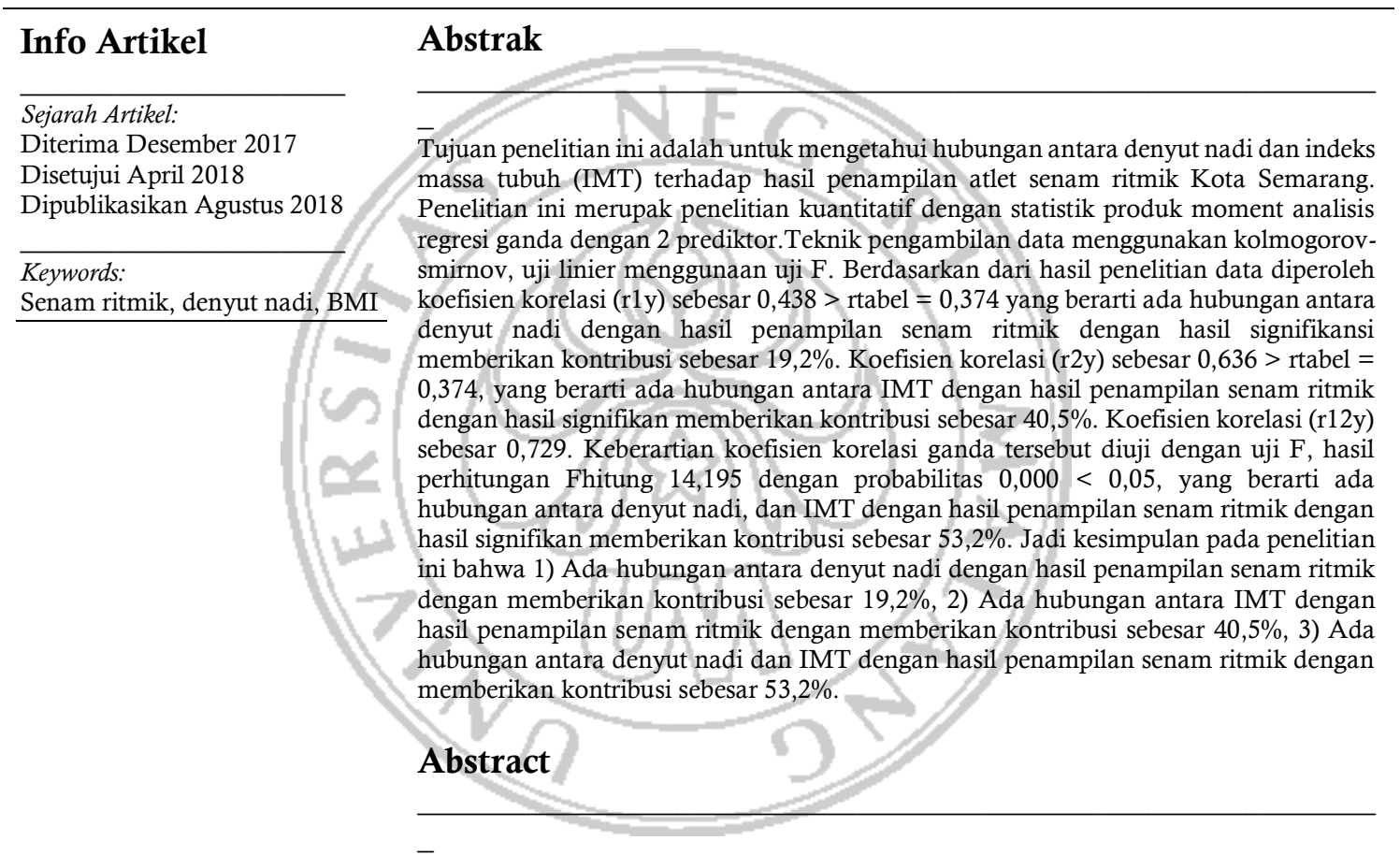

The purpose of this study was to determine the relationship between pulse rate and body mass index (BMI) on the performance of rhythmic gymnastics athletes in Semarang. This research is quantitative research with product moment statistic of multiple regression analysis with 2 predictors. Collecting data technique using kolmogorovsmirnov, linear test using $\mathrm{F}$ test. Based on the research data obtained correlation coefficient $(\mathrm{r} 1 \mathrm{y})$ of $0.438>$ rtabel $=0.374$ which means there The relationship between the pulse with rhythmic exercise results with the results of significance contributed $19.2 \%$. The correlation coefficient $(\mathrm{r} 2 \mathrm{y})$ is $0.636>\mathrm{rtabel}=0.374$, which means there is a relationship between BMI with rhythmic exercise results with significant results contributing $40.5 \%$. The correlation coefficient ( $112 \mathrm{y})$ is 0.729 . The significance of the double correlation coefficient was tested by $\mathrm{F}$ test, the calculation result Fhitung 14,195 with probability $0.000<0,05$, meaning there is relation between pulse, and IMT with result of rhythmic gymnastics appearance with significant result give contribution equal to $53,2 \%$. So the conclusion in this research that 1 ) There is relation between pulse with rhythmic gymnastic performance result by giving contribution equal to $19,2 \%, 2$ ) There is relation between IMT with result of rhythmic gymnastic performance by giving contribution equal to $40,5 \%, 3$ ) There The relationship between pulse rate and BMI with the results of rhythmic gymnastics performance by contributing $53.2 \%$.

(C) 2018 Universitas Negeri Malang 


\section{PENDAHULUAN}

Senam adalah salah satu aktivitas jasmani yang efektif untuk mengoptimalkan pertumbuhan dan perkembangan anak dengan merangsang perkembangan komponen kebugaran jasmani seperti kekuatan, keseimbangan dan daya tahan otot dari seluruh bagian tubuh. Gerakan-gerakan yang terdapat dalam senam sangat sesuai untuk mengisi program pembelajaran jasmani.

Senam sendiri masuk di Indonesia mulai dikenal pada tahun 1912 pada jaman penjajahan Belanda. Masuknya olahraga senam tersebut menjadikan pendidikan jasmani pelajaran wajib di sekolah. Dengan sendirinya senam sebagai bagian dari penjaskes juga diajarkan di sekolah(Agus Mahendra, 2000:1).

Pendidikan itu sendiri berlangsung seumur hidup untuk membantu pertumbuhan dan perkembangan jasmani dan rohani yang sehat maka peran olahraga itu sendiri sangat diperlukan.

Masukanya senam di Indonesia dikenal sebagai salah satu cabang olahraga yang merupakan terjemahan dari bahasa inggris yaitu Gymnastics atau belanda Gymnastiek. Sedangkan Gymnastics sendiri merupakan serapan kata dari bahasa Yunani dari bahasa aslinya, Gymnos yang berarti telanjang.

Pada jaman dahulu perlombaan senam dilakukan dengan telanjang atau setengah telanjang. Hal ini bisa terjadi karena teknologi pembuatan bahan pakaian belum semaju sekarang sehingga belum memungkinkan membuat pakaian yang bersifat lentur mengikuti gerak pemakaiannya.

Sedangkan menurut Peter $\mathrm{H}$. Wenner (1994) mengatakan bahwa : "senam dapat diartikan sebagai bentuk latihan tubuh pada lantai pada alat yang dirancang untuk meningkatkan daya tahan untuk meningkatkan daya tahan, kekuatan, kelentukan, kelincahan, koordinasi, serta kontrol tubuh".

Salah satu senam yang diperlombakan adalah senam ritmik atau senam irama, yaitu gerakan senam yang dilakukan dalam irama musik, atau latihan bebas yang dilakukan secara berirama. Senam ritmik menggunakan alat-alat yang dipegang (hand aparatus) seperti bola, tali, simpai, gada, pita (H.T.Sukarma, 2001:21).

Keanggunan dan keindahan gerakan dikembangkan dengan keterampilan fisik seperti fleksibilitas yang memainkan peran penting dalam olahraga karena kebutuhan untuk melakukan berbagai gerakan. Semakin bertambah umur seseorang, maka tingkat flexibilitynya akan semakin berkurang atau menurun (Apta Mylsidayu dan Febi Kurniawan, 2002:124).

Ada beberapa keuntungan bagi atlet yang mempunyai kualitas flexibility yang baik, antara lain 1) akan memudahkan atlet dalam menampilkan berbagai kemampuan gerak dan keterampilannya, 2) menghindarkan diri dari kemungkinan terjadinya cedera pada pada saat akan melakukan aktivitas fisik, 3) memungkinkan atlet untuk dapat melakukan gerakan yang ekstrim, 4) memperlancar aliran darah sehingga sampai pada serabut otot (Sukadiyanto, 2005:128).

Prestasi suatu cabang olahraga senam ritmik pada dasarnya dipengaruhi dari banyak faktor yang saling terkait, dan masing-masing menyumbangkan peranannya kepada pencapaian prestasi tersebut. Faktor-faktor di atas meliputi faktor atlet sendiri, faktor kualitas latihan dan faktor pendukung lainnya (DepDiknas, 2004: 1).

Dalam faktor yang berkaitan dengan atlet, termasuk berbagai kualitas yang seharusnya dimiliki oleh atlet, dari mulai faktor fisik, faktor motorik, faktor mental dan emosional, serta tak kalah pentingnya faktor anthropometrik. Kesemua faktor tersebut pada gilirannya menjadi faktor penentu yang paling penting.

Kinerja atlet sangat tergantung pada koordinasi motorik dan keterampilan seperti keseimbangan postur, yang digunakan untuk ketepatan gerak saat melakukan suatu gerakan. Prinsip dasar aktivitas ritmik adalah irama (ritme), kelentukan tubuh, serta kontinuitas gerakan dalam setiap performance.

Rangkaian senam irama dapat dilakukan dengan cara berjalan, berlari, melompat, loncat, serta ayunan, dan putaran tangan. Prinsip dasar aktivitas ritmik adalah irama (ritme), kelentukan tubuh, serta kontinuitas gerakan (Muhajir : 2007). Gerakan dalam senam irama lebih mengutamakan pembentukan sikap, keharmonisan, dan keindahan gerak tubuh.

Dalam perlombaan, kondisi fisik menjadi peran yang penting. Dengan kondisi fisik yang kuat atlet akan memiliki daya tahan yang bagus baik untuk anak-anak maupun orang dewasa.

Dalam melakukan gerakan senam ritmik setiap atlet membutuhkan daya tahan yang kuat. Latihan yang teratur menyebabkan otot jantung beradaptasi sehingga jantung menjadi lebih tebal 
dan kuat membuat kerja jantung menjadi efisien dan denyut nadi menjadi stabil (Guyton et al, 2006). Saat latihan anak-anak cepat kelelahan, nafasnya terengah-enggah sehingga membuat anak itu kurang maksimal dalam melakukan gerakan. Seorang atlet setiap hari harus memperhatikan kondisi fisiknya agar dapat tampil secara prima dalam setiap pertandingan, dalam proses latihan untuk dapat meningkatkan prestasi, dengan melakukan latihan atau aktivitas olahraga secara teratur dalam jangka waktu yang lama dapat menurunkan denyut jantung (William and Wilkins, 2012). Salah satu terciptanya kondisi fisik yang baik adalah dengan daya tahan, daya tahan yang baik bisa dilihat dari detakan jantung permenit yang dapat diukur dengan mengukur denyut nadi dengan palpasi (meraba) di pergelangan tangan lalu mengukur denyut nadi dengan menghitung 1 menit. Pengukuran denyut nadi berdasarkan dari denyut nadi normal 85-100 kali permenit.

Aktivitas olahraga dapat meningkatkan denyut nadi, hal ini disebabkan berkurangnya konsumsi oksigen dan bahan bakar energi ke otot maka kerja jantung secara otomatis akan meningkat. Denyut jantung memiliki hubungan linier dengan meningkatnya beban kerja dan konsumsi oksigen (William and Wilkins, 2012:363).

Peningkatan denyut nadi akan berpengaruh terhadap penampilan apabila seorang atlet tidak dapat mengatur kondisi fisiknya dengan baik. Penampilan yang baik dapat tercipta jika seorang atlet mampu menyelesaikan rangkaian gerakan yang tidak terputus. Gerakan yang dilakukan saat tampil bisa jadi kurang intensif karena daya tahan yang dialirkan oksigen dari jantung berkurang sehingga gerakan menjadi patah-patah tidak sesuai irama.

Penelitian yang dilakukan di laboratorium Faal Universitas Airlangga menyimpulkan bahwa aktivitas fisik dapat mempengaruhi peningkatan denyut nadi, hal ini terlihat dari rerata denyut nadi testi pra latihan 63,3 kali permenit sedangkan pasca aktivitas fisik pada menit ke-1 124 kali permenit (Elly IMS, 2006).

Postur tubuh menjadi salah satu faktor yang berpengaruh dalam penampilan atlet dalam olahraga. Seorang olahragawan harus memiliki berat badan ideal atau IMT ideal. agar dalam melakukan aktifitas fisik tidak ada gangguan dari berat tubuh, sehingga mengharuskan untuk menjaga berat badan pada titik keidealan yang sudah di tentukan. Begitupun seorang atlet senam ritmik dituntut memiliki bentuk badan yang ideal agar tidak menghambat gerakan dan kualitas atlet maksimal dalam mempraktikan gerakan, dapat menjaga keseimbangan dengan benar sehingga dalam melakukan rangkaian gerakan secara maksimal tidak mendapat potongan nilai dari juri.

Beberapa cabang olahraga, postur tubuh yang tinggi dengan berat badan ideal dan kondisi fisik yang baik akan menunjang pencapaian prestasi olahraga yang tinggi (Sri Haryono, 2008:3). Seperti halnya senam ritmik, penampilan menjadi salah satu hal yang dinilai, semakin ideal postur tubuh seorang atlet semakin maksimal dalam melakukan suatu gerakan dengan baik dan mudah. Aspek biologis yang berupa struktur postur tubuh seperti halnya tinggi badan adalah salah satu penentu pencapaian kemampuan dalam olahraga (M.Sajoto, 1995:2).

Tinggi badan merupakan antropometri yang menggambarkan keadaan pertumbuhan skeletal, sedangkan berat badan adalah salah satu parameter yang memberikan gambaran massa tubuh. Berat badan memiliki hubungan yang linear dengan tinggi badan. Keadaan normal, perkembangan berat badan searah dengan pertumbuhan tinggi badan dengan kecepatan tertentu.

IMT adalah nilai yang diambil dari perhitungan antara berat badan (BB) dan tinggi badan (TB) seseorang. Berat badan adalah salah satu parameter yang memberikan gambaran massa tubuh. Tinggi badan merupakan parameter yang penting bagi keadaan yang telah lalu dan keadaan sekarang, jika umur tidak diketahui dengan tepat (Supariasa, 2002).

- Seorang pesenam harus memperhatikan indeks massa tubuh, karena seorang pesenam akan terlihat lebih indah saat melakukan gerakan senam yang akan mempengaruhi pada nilai kualitas senam tersebut. Pesenam memiliki berat badan ideal maka pada seorang pesenam tidak akan terhalang atau terhambat gerakan senamnya oleh berat badannya. Aspek penentu pestasi Senam salah satunya adalah Sumbangan Aspek Morfologis Terhadap Prestasi Senam(Agus Mahendra : 2002).

Menurut prosedur Principal Component Analysis (PCA) diterapkan dalam penelitiannya, per-formance yang sukses dalam senam ritmik tergantung pada 6 komponen: karakteristik antropometri, fleksibilitas, kekuatan ledakan, kapasitas aerobik, dimensi tubuh, dan metabolisme anaerobik. Pengetahuan tentang pentingnya komponen ini sangat membantu bagi pelatih yang menginvestasikan waktu dan usaha untuk sangat berhasil dalam menuntut 
mendisiplinkan. Salah satu temuan utama adalah bahwa skor kinerja senam ritmik berpangkat secara signifikan dijelaskan oleh komponen antropometri dan kapasitas aerobik, dan perlu dicatat bahwa yang terakhir itu diidentifikasi sebagai prediktor pertama dalam senam ritmik elit antropometri athletes (Douda, 2008:50).

Tentunya dengan bentuk tubuh yang ideal seorang pesenam akan lebih mudah dan maksimal dalam melakukan gerakan senam tidak menghambat seorang pesenam untuk bergerak cepat lincah dan jika kelincahan dan kecepatan terhambat akan mengurangi nilainilai kualitas gerakan senam karena seorang pesenam akan terlihat lebih indah saat melakukan gerakan senam yang akan mempengaruhi pada nilai kualitas senam tersebut.

Di dalam olahraga senam ritmik diperlukan daya tahan yang baik untuk dapat menunjang prestasi. Dengan daya tahan yang baik tentu hasil penampilan atlet juga akan baik, namun banyak atlet yang belum mengetahui peningkatan nadi, dan recovery yang baik itu mempengaruhi hasil penampilan karena selama latihan tidak pernah melakukan pengukuran denyut nadi dan lama latihanpun juga berpengaruh dengan daya tahan atlet. Hal tersebut tentunya akan berpengaruh saat tampil dalam perlombaan dimana atlet melakukan serangkaian gerakan selama 1 menit 30 detik tanpa henti. Selain itu IMT lebih banyak mempengaruhi hasil penampilan senam ritmik, karena di CoP senam ritmik dijelaskan bahwa atlet yang melakukan heavy landing akan mendapat potongan nilai dari juri.

Berdasarkan latar belakang di atas, peneliti bermaksud ingin mengadakan penelitian dengan judul "Korelasi Antara Denyut Nadi Dan IMT Terhadap Hasil Penampilan Senam Ritmik Popda Sd Kota Semarang Tahun 2017". Yang diharapkan dapat memberikan masukan bagi pelatih dan atlet di Kota Semarang pada khususnya mengenai denyut nadi dan IMT guna meningkatkan prestasi.

Adapun tujuan utama yang hendak di capai melalui penelitian ini adalah: (1) untuk mengetahui besarnya hubungan antara denyut nadi dengan hasil penampilan atlet senam ritmik, (2) untuk mengetahui besarnya hubungan antara IMT dengan hasil penampilan atlet senam ritmik (3) Untuk mengetahui besarnya hubungan antara denyut nadi dan IMT terhadap hasil penampilan senam ritmik POPDA SD Kota Semarang tahun 2017, (4) Untuk mengetahui besarnya kontribusi antara denyut nadi dan IMT terhadap hasil penampilan senam ritmik POPDA SD Kota Semarang tahun 2017.

\section{METODE}

Metode yang digunakan dalam penelitian ini adalah metode survey test. Dalam penelitian ini sebagai populasi adalah semua peserta senam ritmik POPDA SD Kota Semarang tahun 2017. Dengan desain penelitian korelasional.. Teknik pengambilan sampel menggunakan teknik total sampling yaitu seluruh atlet POPDA SD Kota Semarang Cabang Olahraga Senam Ritmik Tahun 2017, dengan jumlah sampel 28 orang.

Variabel penelitian yang digunakan menggunakan variabel bebas dan variabel terikat. Variabel bebas merupakan variabel yang mempengaruhi variabel terikat. Ada dua variabel bebas (X) yaitu: denyut nadi dan indeks massa tubuh (IMT). Variabel terikat adalah variabel yang dipengaruhi variabel bebas. Variabel terikat dalam penelitian ini adalah hasil penampilan senam ritmik atlet POPDA SD tahun 2017.

Teknik pengambilan sampel menggunakan teknik tes dan pengukuran. Metode analisis yang digunakan adalah korelasi product moment analisis regresi ganda dengan 2 prediktor.

\section{HASIL}

Hasil penelitian berdasarkan analisis deskriptif survei tes dan pengukuran menggunakan statistik korelasi product moment. Berdasarkan hasil analisis korelasi antara denyut nadi dengan penampilan senam ritmik SD Kota Semarang tahun 2017 diperoleh hasil seperti terlihat pada tabel berikut ini:

\section{Hubungan antara Denyut Nadi dengan Penampilan Senam Ritmik Popda SD Kota Semarang}

Tabel 1. Koefisien Korelasi Denyut Nadi dengan Penampilan Senam Ritmik Popda SD Kota Semarang

\begin{tabular}{|c|c|c|c|c|}
\hline Model & $\mathrm{R}$ & R Square & Adjusted R Square & Std. Error of the Estimate \\
\hline & $.438^{\mathrm{a}}$ & .192 & .161 & 1.25853 \\
\hline
\end{tabular}

Predictors: (Constant), Denyut nadi 
Dalam tabel di atas diperoleh koefisien korelasi sebesar 0,438. Uji keberatian koefisien korelasi tersebut dilakukan dengan cara mengonsultasi harga $r_{\text {hitung }}$ dengan $r$ product moment. Pada $\alpha=5 \%$ dengan $\mathrm{N}=28$ diperoleh $r_{\text {tabel }}=0,374$. atau $0,438>0,374$, berarti ada hubungan denyut nadi dengan penampilan senam ritmik SD Kota Semarang tahun 2017.

Tabel 2. Koefisien Regresi Denyut Nadi dengan Penampilan Senam Ritmik

\begin{tabular}{|c|c|c|c|c|c|c|}
\hline & & & Coefficients $^{\mathrm{a}}$ & & & \\
\hline \multirow{2}{*}{\multicolumn{2}{|c|}{ Model }} & \multicolumn{2}{|c|}{ Unstandardized Coefficients } & Standardized & \multirow[t]{2}{*}{$\mathrm{T}$} & \multirow[t]{2}{*}{ Sig. } \\
\hline & & $\mathrm{B}$ & Std. Error & Beta & & \\
\hline \multirow{2}{*}{1} & (Constant) & .748 & 2.143 & & .349 & .730 \\
\hline & Denyut nadi & .037 & .015 & .438 & 2.483 & .020 \\
\hline
\end{tabular}

Dependent Variable: Penampilan senam ritmik

Setiap terjadi kenaikan denyut nadi dengan penampilan senam ritmik sebesar 1 point, akan diikuti pula kenaikan penampilan senam ritmik sebesar 0,037 point pada konstanta 0,748 . Dengan kata lain untuk memperoleh hasil penampilan senam ritmik yang optimum, dibutuhkan denyut nadi yang tinggi, begitu juga dengan sebaliknya.

\section{Hubungan Indeks Massa Tubuh dengan penampilan senam ritmik}

Tabel 3. Koefisien Korelasi Indeks Massa Tubuh dengan Penampilan Senam Ritmik Model Summary

\begin{tabular}{|l|r|r|r|r|}
\hline Model & R & R Square & Adjusted R Square & Std. Error of the Estimate \\
\hline 1 & $.636^{\mathrm{a}}$ & .405 & .382 & 1.08013 \\
\hline
\end{tabular}

Predictors: (Constant), IMT

Dalam tabel di atas diperoleh koefisien korelasi sebesar 0,636. Uji keberatian koefisien korelasi tersebut dilakukan dengan cara mengonsultasi harga $r_{\text {hitung dengan } r}$ product moment. Pada $\alpha=5 \%$ dengan $\mathrm{N}=28$ diperoleh $r_{\text {tabel }}=0,374$ atau $0,636>0,374$, berarti ada hubungan antara indeks massa tubuh dengan penampilan senam ritmik Popda SD Kota Semarang tahun 2017.

Tabel 4. Koefisien Regresi Indeks Massa Tubuh Dengan Penampilan Senam Ritmik Coefficients $^{\mathrm{a}}$

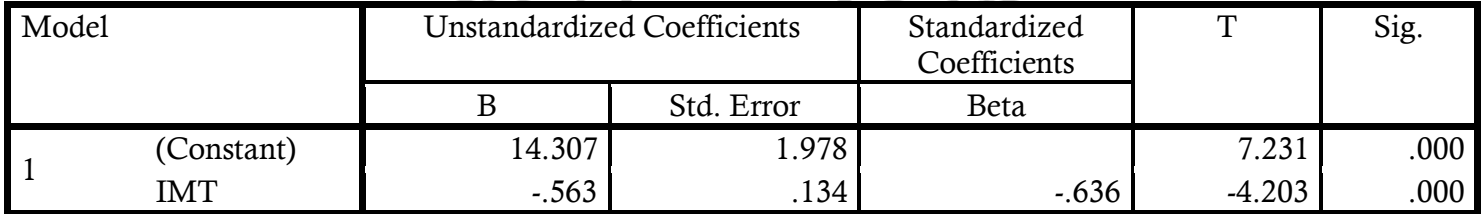

Dependent Variable: Penampilan senam ritmik

Berdasaran hasil perhitungan, sumbangan efektif dari variabel IMT terhadap hasil penampilan senam ritmik adalah sebesar $40,5 \%$, derajat hubungan IMT dengan penampilan senam ritmik tersebut dapat di lihat dari besarnya koefisien korelasi yang diperoleh yaitu sebesar $-0,563$.

\section{Hubungan antara Denyut Nadi dan IMT dengan Hasil Penampilan Senam Ritmik}

Tabel 5. Koefisien Korelasi Indeks Massa Tubuh dengan Penampilan Senam Ritmik

Model Summary

\begin{tabular}{|l|r|r|r|r|}
\hline Model & R & R Square & Adjusted R Square & Std. Error of the Estimate \\
\hline 1 & $.636^{\mathrm{a}}$ & .405 & .382 & 1.08013 \\
\hline
\end{tabular}

Predictors: (Constant), IMT

Dalam tabel di atas diperoleh koefisien korelasi sebesar 0,636. Uji keberatian koefisien 
korelasi tersebut dilakukan dengan cara mengonsultasi harga $r_{\text {hitung }}$ dengan $r$ product moment. Pada $\alpha=5 \%$ dengan $\mathrm{N}=28$ diperoleh $r_{\text {tabel }}=0,374$ atau $0,636>0,374$, berarti ada hubungan antara indeks massa tubuh dengan penampilan senam ritmik Popda SD Kota Semarang tahun 2017.

Tabel 6. Koefisien Regresi Indeks Massa Tubuh Dengan Penampilan Senam Ritmik Coefficients $^{\mathrm{a}}$

\begin{tabular}{|rl|r|r|r|r|r|}
\hline \multirow{2}{*}{ Model } & \multicolumn{2}{|c|}{ Unstandardized Coefficients } & \multicolumn{1}{c|}{$\begin{array}{c}\text { Standardized } \\
\text { Coefficients }\end{array}$} & \multirow{2}{*}{ S } & \\
\cline { 3 - 5 } & & \multicolumn{1}{|c|}{ B } & Std. Error & Beta & & \\
\hline \multirow{2}{*}{1} & (Constant) & 14.307 & 1.978 & & 7.231 & .000 \\
\hline & IMT & -.563 & .134 & -.636 & -4.203 & .000 \\
\hline
\end{tabular}

Dependent Variable: Penampilan senam ritmik

Berdasaran hasil perhitungan, sumbangan efektif dari variabel IMT terhadap hasil penampilan senam ritmik adalah sebesar $40,5 \%$, derajat hubungan IMT dengan penampilan senam ritmik tersebut dapat di lihat dari besarnya koefisien korelasi yang diperoleh yaitu sebesar $-0,563$.

Tabel 7. Hubungan antara Denyut Nadi dan IMT dengan Hasil Penampilan Senam Ritmik Model Summary

\begin{tabular}{|r|r|r|r|r|}
\hline \multicolumn{1}{|c|}{ Model } & \multicolumn{1}{|c|}{ R } & \multicolumn{1}{c|}{ R Square } & Adjusted R Square & Std. Error of the Estimate \\
\hline 1 & $.729^{\mathrm{a}}$ & .532 & .494 & .97682 \\
\hline
\end{tabular}

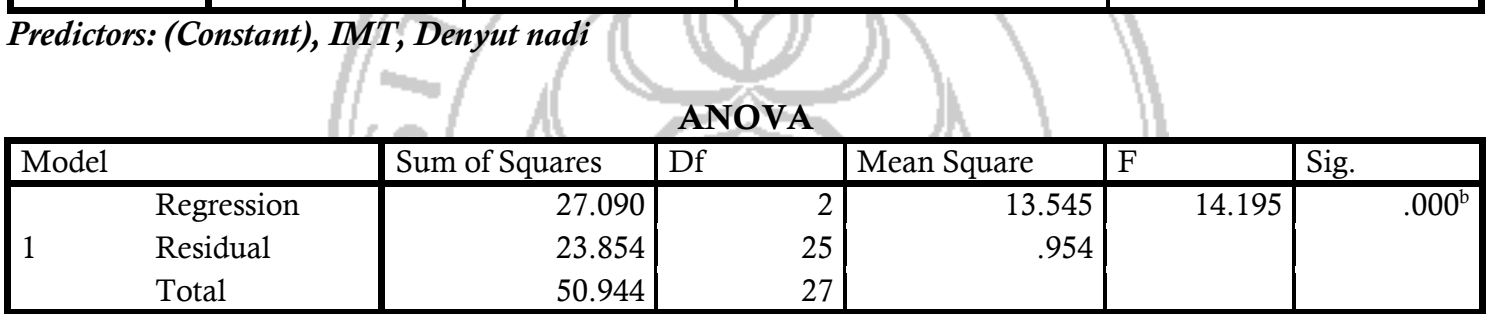

a. Dependent Variable: Penampilan senam ritmik

b. Predictors: (Constant), IMT, Denyut nadi

Dalam tabel di atas diperoleh koefisien korelasi sebesar 0,729, koefisien korelasi ganda tersebut diuji keberartiannya menggunakan uji $\mathrm{F}$, diperoleh $\mathrm{F}_{\text {hitung }}=14,195$ dengan probabilitas $0,000<0,05$, yang berarti hipotesis kerja $(\mathrm{Ha})$ diterima. Dengan diterimanya hipotesis kerja (Ha) ini dapat disimpulkan bahwa ada hubungan denyut nadi dan IMT dengan hasil

Tabel 8. Kontribusi Denyut Nadi terhadap Hasil Penampilan Senam Ritmik Model Summary ${ }^{\mathrm{b}}$

\begin{tabular}{|l|r|r|r|r|r|}
\hline Model & $\mathrm{R}$ & R Square & $\begin{array}{c}\text { Adjusted R } \\
\text { Square }\end{array}$ & $\begin{array}{c}\text { Std. Error of the } \\
\text { Estimate }\end{array}$ & Durbin-Watson \\
\hline 1 &, $438^{\mathrm{a}}$ &, 192 &, 161 & 1,25853 & 1,361 \\
\hline
\end{tabular}

a. Predictors: (Constant), Denyut nadi

b. Dependent Variable: Penampilan senam ritmik

Pada tabel diperoleh harga $\mathrm{R}^{2}$ sebesar 0.192. Dengan demikian besar pengaruh denyut nadi terhadap penampilan senam ritmik sebesar $19,2 \%$ penampilan senam ritmik Popda SD Kota Semarang tahun 2017.

4. Kontribusi Denyut Nadi terhadap Hasil Penampilan Senam Ritmik 
Tabel 9. Kontribusi IMT terhadap Hasil Penampilan Senam Ritmik Model Summary

\begin{tabular}{|l|r|r|r|r|r|}
\hline Model & \multicolumn{1}{|c|}{$\mathrm{R}$} & R Square & $\begin{array}{c}\text { Adjusted R } \\
\text { Square }\end{array}$ & $\begin{array}{c}\text { Std. Error of the } \\
\text { Estimate }\end{array}$ & Durbin-Watson \\
\hline 1 &, $636^{\mathrm{a}}$ &, 405 &, 382 & 1,08013 & 1,545 \\
\hline
\end{tabular}

a. Predictors: (Constant), IMT

b. Dependent Variable: Penampilan senam ritmik

Pada tabel diperoleh harga $\mathrm{R}^{2}$ sebesar 0.405. Dengan demikian besar pengaruh IMT terhadap penampilan senam ritmik sebesar $40,5 \%$.

\section{Kontribusi antara Denyut Nadi dan IMT terhadap Hasil Penampilan Senam Ritmik}

Tabel 10. Kontribusi antara Denyut Nadi dan IMT terhadap Hasil Penampilan Senam Ritmik Model Summary $^{\mathrm{b}}$

\begin{tabular}{|l|r|r|r|r|r|}
\hline Model & $\mathrm{R}$ & R Square & Adjusted R Square & $\begin{array}{c}\text { Std. Error of the } \\
\text { Estimate }\end{array}$ & Durbin-Watson \\
\hline 1 &, $729^{\mathrm{a}}$ &, 532 &, 494 &, 97682 & 1,506 \\
\hline
\end{tabular}

a. Predictors: (Constant), IMT, Denyut nadi

b. Dependent Variable: Penampilan senam ritmik

Pada tabel diperoleh harga $\mathrm{R}^{2}$ sebesar 0.532. Dengan demikian secara bersama-sama denyut nadi dan IMT berpengaruh/dengan penampilan senam ritmik $53,2 \%$.

\section{PEMBAHASAN}

Dari teori yang didapat daya tahan yang baik tidak akan menghasilkan denyutan nadi yang banyak. Untuk mendapatkan hasil penampilan senam ritmik yang baik diperlukan daya tahan yang baik pula. Semakin baik kualitas daya tahan anaerobnya, semakin siap pesenam dalam melakukan serangkaian gerakan yang bermacam-macam, yang biasanya memiliki intensitas progresif, yaitu semakin lama semakin tinggi intensitasnya, dan diakhiri dengan sebuah klimaks (Agus Mahendra, 2002).

Berdasarkan hasil analisis data diatas, telah dibuktikan bahwa ada hubungan yang signifikan antara denyut nadi dengan hasil penampilan senam ritmik walaupun keterkaitan keduanya berbanding terbalik dengan teori yang ada tetapi tidak terlalu berpengaruh karena kenaikan denyut nadi masih aman, masih dalam batas denyut nadi zona latihan dan tidak melebihi denyut nadi maksimal.

Harga koefisien regresi imt terhadap hasil penampilan senam ritmik yang bertanda negatif berbalik arah dan sesuai dengan teori yang ada. Hasil negatif didapat dari hasil penelitian semakin tinggi nilai imt atlet semakin rendah hasil penampilan, hal tersebut berarti apabila nilai imt menurun, maka hasil penampilan senam ritmik akan meningkat dan sebaliknya, apabila nilai imt meningkat maka hasil penampilan senam ritmik akan menurun.

Adanya hubungan yang cukup erat antara imt dengan hasil penampilan senam ritmik dikarenakan semakin tinggi nilai imt semakin rendah hasil nilai penampilan yang didapat. Dari hasil penelitian yang didapat ( lihat lampiran 10 hal 89) hasil penampilannya paling tinggi 8,5 dengan imt nya 12 . Atlet dengan hasil penampilan terendah 3,9 imt nya 14,3. Atlet dengan nilai imt semakin rendah semakin baik hasil penampilannya.

Mengacu dari kenyataan tersebut, maka dalam upaya meningkatkan prestasi atlet senam ritmik, imt perlu diperhatikan karena dengan bentuk tubuh yang ideal seorang pesenam akan lebih mudah dan maksimal dalam melakukan gerakan senam tidak menghambat seorang pesenam untuk bergerak cepat lincah dan jika kelincahan dan kecepatan terhambat akan mengurangi nilai-nilai kualitas gerakan senam dan tentunya akan mendapat potongan oleh juri senam ritmik. Seorang pesenam ritmik dituntut memiliki bentuk badan berat badan idela dibawah ambang batas, ramping, tinggi kurus, komposisi kaki lebih panjang dari pada badan, kaki tidak berbentuk $x$, tidak berbentuk o agar faktor flexibilitas itu terlihat indah. Pernyataan ini sesuai dengan hasil rangkuman wawancara dari ketiga pelatih senam ritmik. 


\section{KESIMPULAN}

Berdasarkan hasil analisis data, deskripsi, pengujian hasil penelitian, dan pembahasan, dapat diambil kesimpulan bahwa terdapat hubungan positif dan signifikan antara denyut nadi terhadap penampilan senam ritmik Popda SD Kota Semarang tahun 2017. Terdapat hubungan negatif dan signifikan antara IMT terhadap penampilan senam ritmik Popda SD Kota Semarang tahun 2017. Secara bersamasama terdapat hubungan yang positif maupun negatif dan signifikan antara denyut nadi dan IMT terhadap penampilan senam ritmik Popda SD Kota Semarang tahun 2017. Terdapat kontribusi sebesar $53,2 \%$ antara denyut nadi dan IMT terhadap penampilan senam ritmik Popda SD Kota Semarang tahun 2017.

\section{DAFTAR PUSTAKA}

Mahendra A. 2001. SENAM. Semarang DEPDIKBUD

Mylsidayu A, \& Kurniawan F. 2015. Ilmu Kepelatihan Dasar. Bandung : Alfabeta.

Depdiknas (2004). Instrumen Pemanduan Bakat Senam. Jakarta. Direktorat Olahraga Pelajar dan Mahasiswa.

Irianto. D P. 2002. Dasar Kepelatihan. Yogyakarta: Surat Perjanjian Pelaksanaan Penulisan Diklat

Douda Helen T, Argyris G. Toubekis, Alexandra A. Avloniti, and Savvas P. Tokmakidis. International Journal of Sports Physiology and Performance, 2008,3,41-54

Guyton A C. Hall J E. 2005. Fisiologi Kedokteran. Jakarta: Penerbit Buku Kedokteran. EGC. PP: 137, 147

H.T. Sukarma. 2001. Senam Ritmik BentukBentuk Tugas Ajar \& Pembelajaran. Jakarta: Depdiknas

Supariasa, I D N, dkk. 2002. Penilaian Status Gizi. Jakarta: B

Kraemer W J, Steven J F and Michaele R D. Exercise Physiology. China: 2012 